
\title{
$\begin{array}{ll}\text { Research Square } & \text { They should not be considered conclusive, used to inform clinical practice, } \\ \text { or referenced by the media as validated information. }\end{array}$
}

\section{"Will my Young Adult Years be Spent Socially Distancing?": A Qualitative Exploration of UK Adolescents' Lockdown Experiences during the COVID-19 Pandemic}

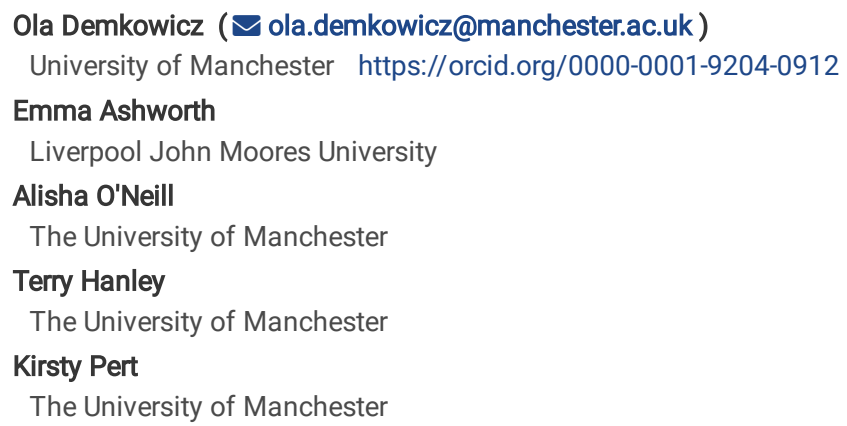

The University of Manchester

Terry Hanley

The University of Manchester

Kirsty Pert

The University of Manchester

\section{Research article}

Keywords: Adolescence, wellbeing, mental health, adolescent mental health, coping, self-care, COVID-19, lockdown, social distancing, pandemic

Posted Date: June 17th, 2021

DOI: https://doi.org/10.21203/rs.3.rs-451696/v2

License: (c) (i) This work is licensed under a Creative Commons Attribution 4.0 International License. Read Full License 


\section{Abstract}

Background and Aims: For older adolescents, the COVID-19 pandemic and associated UK restrictions arrived during a critical period in the transition to adulthood. Early research exploring impact of the pandemic paints a picture of worsened adolescent wellbeing and mental health. We explore the subjective experiences of 16- to 19-year-olds during the first UK lockdown, with an emphasis on wellbeing and coping, in order to complement emergent quantitative evidence and inform strategies and provision for support.

Methods: In May 2020, we invited UK-based 16- to 19-year-olds to share their experiences of the initial lockdown for '[project name redacted for blinded peer review]'. 109 participants took part, submitting anonymous written accounts via an online portal. We used inductive reflexive thematic analysis to develop rich experiential themes.

Findings: We constructed seven main themes: heightened emotionality; feelings of loss, change, and uncertainty; recognising the value of self-care; efforts to think positively; opportunities for relief, growth, and development; the importance of togetherness; and frustration with government and media.

Implications: Findings highlight the multifaceted nature of adolescents' lockdown experiences, and offer insight into emotional impact and new concerns as well as the value placed on self-care and staying connected. We offer directions for supporting adolescents as pandemic consequences continue.

\section{Background}

On March 23, 2020, the United Kingdom (UK) Government implemented a lockdown in response to the novel coronavirus disease 2019 (COVID-19) pandemic. This included strict restrictions on face-to-face social contact, time spent outdoors, and ability to work, as well as severely reduced access to school and education services. Though such measures were intended to slow the progression of COVID-19, concerns were raised about the possible short- and long-term impacts for mental health and wellbeing (Holmes et al., 2020). Indeed, evidence suggests that by late April, mental health among UK individuals aged 16 and above had worsened when compared to pre-COVID-19 trends (Pierce et al., 2020). Notably, evidence has suggested that the impact of restrictions was not equal across groups, with some individuals at greater risk of distress and poor mental health than others, and indications of growing mental health inequalities (James Banks \& Xu, 2020; Fancourt et al., 2020; Pierce et al., 2020).

Specifically, early in the pandemic, researchers raised initial concerns about the potential impact for adolescents and young people as one of several groups potentially at risk (Clemens et al., 2020; Holmes et al., 2020; The Lancet Child \& Adolescent Health, 2020). These younger groups faced considerable disruption to daily life, reduced access to support, and the threat of COVID-19 for themselves and their loved ones, all during an already vulnerable period for mental health (Jones, 2013; Kessler et al., 2005). Initial evidence seems to have corroborated such concerns, to an extent. Pierce and colleagues (Pierce et al., 2020) tracked UK population-level mental health before and during the pandemic and identified an overall increase in mental distress in young adults aged 18-24, while Banks and Xu (James Banks \& Xu, 2020) reported worsened mental health trends among young adults aged 16-25 during the pandemic compared to previous years. Fancourt et al. (2020) have reported that younger adults in the UK reported greater levels of anxious and depressive symptoms in the initial stages of the March lockdown, though interestingly they also found that this group seemed to show a quicker recovery compared to older adults. UK charity organisations have also reported that young people appeared to be experiencing increased feelings of distress and anxiety during lockdown (NSPCC Learning, 2020; The Prince's Trust \& YouGov, 2020), alongside increased presentation of self-harm and suicidal thoughts (Kooth, 2020). Evidence from other countries has echoed these trends, indicating greater distress and anxiety among adolescents and young adults (Chen et al., 2020; Newby et al., 2020; Save the Children, 2020; Xiong et al., 2020). We note that many (but not all) such studies have relied on convenience samples, necessitating caution, and at the time of writing there remains limited peer-reviewed empirical evidence relating to younger adolescents compared with broad adult populations. However, taken together, emerging evidence indicates vulnerability among adolescents and young people in the context of COVID-19 restrictions, and highlights the need for further exploration of experiences and key issues among these age groups.

For older UK adolescents aged 16- to 19-years, the COVID-19 pandemic and restrictions arrived during a key moment in the transition to adulthood. Late adolescents tend to be increasingly autonomous as neurological and cognitive developmental shifts bring greater self-regulation and ability to conceptualise the consequences of one's actions (G. C. Patton et al., 2016; Umberson et al., 2010; Zarrett \& Eccles, 2006). Considerable emphasis is typically placed on social connection with peers at this time, and indeed evidence indicates that positive (e.g., supportive) peer relationships and friendships are associated with greater psychological wellbeing and reduced mental health symptomatology in late adolescence (Greca et al., 2010; Umberson et al., 2010). Thus, although they are considered low-risk for the physical health impacts of the virus itself (Castagnoli et al., 2020), the UK March 2020 pandemic restrictions brought considerable disruption to "normative" daily life among this group. Being restricted to staying inside, not attending education settings, and only socialising with one's own household (likely to consist of family members), curtailed late adolescents' independence and prohibited in-person interactions with peers and friends. For some, these restrictions have also meant continuous exposure to challenging home circumstances, such as high-conflict family relationships or patterns of domestic abuse or child abuse (Crawley et al., 2020).

Late adolescence also frequently brings educational and vocational shifts. In the UK, this age group typically finish secondary education, engage in some form of further/higher education, go onto further training, or enter the workforce. Thus, this stage encompasses a number of transitions, high stakes examinations, and considerable future-oriented decision-making and planning (G. C. Patton et al., 2016; Zarrett \& Eccles, 2006). In 2020, however, education settings were closed, and key high stakes examinations were cancelled, most notably GCSEs (General Certificate of Secondary Education; a set of exams undertaken nationally at age 15-16) and A Levels (General Certificate of Education Advanced Level). Alternative grading systems were put in place, relying on teacher assessment and prior mock exam results, though it took several months for these decisions to be resolved. Concerns were noted over the uncertainty such shifts could bring for adolescents (The Lancet Child \& Adolescent Health, 2020) and indeed initial international evidence indicated that such disruptions were creating considerable feelings of uncertainty (Scott et al., 2021). 


\section{Rationale}

Early research exploring the impact during the pandemic paints a picture of worsened wellbeing and mental health for older adolescents (James Banks \& Xu, 2020; Fancourt et al., 2020; Pierce et al., 2020). Pandemic restrictions appear to have brought considerable disruption and introduced a number of new challenges that are at odds with normative experiences, which may have adverse consequences for overall wellbeing. Thus, it is imperative to explore older adolescents' experience of lockdown, so that we might learn from their experience and use it to develop strategies to support them through the ongoing pandemic and its aftermath. Notably, initial UK research with adolescents and young people adopted quantitative designs. While monitoring of mental health and wellbeing among the wider population is important at this time, we must also ensure focused investigations among at-risk populations, including through qualitative exploration (Demkowicz et al., 2021; Holmes et al., 2020). Critically, efforts to translate "monitoring" knowledge into meaningful steps for support and provision will be challenging without understanding the subjective experience of young people themselves., Researchers have also been looking to use "pre-COVID-19" knowledge and understanding to inform provision and support for adolescents at this time; however, the novelty of these circumstances means such inferences are not always straightforward (Gilleard et al., 2020). Thus, gaining insight into adolescents' personal experiences of the pandemic is essential if we are to effectively inform policy and practice as the pandemic and its ongoing consequences continue. However, evidence capturing the perspectives of adolescents during the pandemic remains limited. In the current study, we set out to contribute to this developing evidence base by exploring the subjective experiences of older adolescents during the first UK lockdown. Specifically, we focused on understanding how 16- to 19-year-olds make sense of their lockdown experiences, perceive the impact of lockdown on their circumstances, and experience and manage their wellbeing in lockdown.

\section{Method}

\section{Research Design}

The current study ('[project name redacted for blinded peer review]') qualitatively explores subjective experiences of the UK COVID-19 lockdown among adolescents aged 16- to 19-years. We focused on subjective, individualised experiences of lockdown and therefore adopted a qualitative design within a social constructivist lens, which recognises individualised constructions of reality (M. Patton, 2015). Our approach was exploratory, and so we adopted an openended approach within data generation and an inductive approach to analysis, thereby focusing on what was meaningful to participants rather than exploring these phenomena through a specific theoretical or conceptual lens (Braun \& Clarke, 2006). As such we adopt a pragmatic approach to exploring and making sense of findings, drawing pluralistically on relevant theory and conceptualisations to best make sense of these data-driven findings.

Given the study's timeliness amid the COVID-19 pandemic, we outlined key findings in a public-facing rapid report for 16-to 19-year-olds, parents/carers, and those working with this age group (Author 1 et al., 2020 [details redacted for blinded peer review]). Here, we explore data and findings for an academic audience, offering greater depth and detail, examining connections to theory and prior research, and reflecting on implications of findings.

\section{About the researchers}

In line with qualitative research reporting guidelines (American Psychological Association, 2018), we briefly describe the authorship team. We are a team of mixed methods and qualitative adolescent mental health researchers, with specialisms in risk and resilience processes, help-seeking and social support, and school-based provision for wellbeing and mental health. In addition, Author 4 is a counselling psychologist who has over ten years' experience of working as a school-based counsellor and was also a parent to adolescents during the pandemic, and Author 5 is a former secondary school teacher. In designing the current study, we drew on our existing theoretical understanding of adolescent wellbeing and mental health and related processes (e.g., emotion experience, coping, social support) but as noted above we sought to set aside specific theoretical lenses given the study's inductive exploratory approach.

\section{Participants}

109 individuals shared their experiences. We recruited purposively via social media and local and national networks and organisations, with participants volunteering to engage. Inclusion criteria were (a) 16- to 19-years old, and (b) living in the UK. Participants' mean age was 17.6 years ( $S D=1.22)$. 87 participants (79.8\%) identified themselves as girls and women, and a smaller proportion of 22 participants as boys and men (20.2\%). All participants reported being in some form of education; 13 (11.9\%) attending school, 52 (47.7\%) attending further education, 43 (39.4\%) attending higher education, and 1 (0.9\%) attending another form of education. In terms of ethnicity, the sample is broadly similar to the current national pattern recorded for state-funded secondary schools (Department for Education \& Office for National Statistics, 2019); the majority were White $(n=69 ; 63.3 \%)$, followed by Asian ( $n=21,19.3 \%)$, Black $(n=$ $7,6.4 \%)$, mixed $(n=4,3.7 \%)$, Chinese $(n=3,2.8 \%)$, and other $(n=4,3.7 \%)$. The remaining $0.9 \%$ chose not to disclose ethnicity. Four participants disclosed that they had left the UK at some point during lockdown to return to their home country. However, we included these accounts, as these individuals were in the UK for part of the lockdown.

\section{Data Generation}

In May 2020 we invited 16- to 19-year-olds based in the UK to share their experiences of the initial lockdown so far. Participants anonymously submitted written accounts of their experiences via a secure online questionnaire server, SelectSurvey. We used written accounts, rather than virtual interviews or focus groups, to allow participants to take their time, reflect independently without researcher presence, and focus on experiences most salient to them (Braun et al., 2020). Participants remained anonymous to minimise social desirability and facilitate candour (Bouchard, 2016; Braun et al., 2020). Participants could request a certificate for contributions to socially responsible research, an age-appropriate recognition of contributions (Kirby, 2004), which they requested via a separate link to preserve account anonymity.

We offered a single box for writing, to allow participants to focus on what was most personally meaningful, and enable unanticipated points to arise, in line with our inductive approach. Box 1 shows specific instructions and question prompts offered; we provided a broad, open-ended objective, alongside several 
open-ended/neutral question prompts as guidance. We ended with a prompt asking participants for advice to other teenagers, to end positively and provide some personal distance (a summary of this advice is publicly available; Authors 1 and 2, 2020 [details redacted for blinded peer review]. Length of accounts varied widely, from seven to 1,215 words (mean $=213$ ). Participants also provided their age, gender, ethnicity, and education status (as reported above).

\section{Ethical Considerations}

Ethical approval was obtained from The University of Manchester Research Ethics Committee (Ref: 2020-9615-15277); procedures were informed by institutional and wider guidance (The British Psychological Society, 2014). Participants were presented with information outlining the research and gave anonymous consent by clicking to agree that they had read and understood key information and met inclusion criteria. Immediately prior to the writing page, we included a page reminding participants of the expected time completion should take (maximum one hour) and that they should only take part if feeling safe and comfortable to do so and should take a break if needed. We offered signposting at regular intervals, highlighting support services relevant for COVID19 symptoms, unsafe environments, and mental health, and developed a procedure should a participant directly ask for help (this did not arise).

\section{Analysis}

We analysed data using Braun and Clarke's (2006) reflexive thematic analysis. This aligned with our focus on developing rich experiential themes that could capture latent features of the data and offer nuanced insights into participants' subjective experiences. We adopted an inductive approach, focusing on what was meaningful to participants rather than analysing through a specific lens (Braun \& Clarke, 2006).

We followed Braun and Clarke's (2006) six-stage process. We familiarised ourselves with the dataset, and then coded the data inductively, attending to each account in turn. Next, we defined and named themes and developed a written narrative for each. The first three authors (Authors 1,2 , and 3 ) undertook analysis and engaged in regular debriefing and reflexive discussion, consistent with guidance (Nowell et al., 2017). Once we had developed our themes, we engaged in reflexive discussion with another author (Author 4) to explore our decisions and examine where further consideration may be valuable; we then revisited and developed themes accordingly. Our approach was informed by quality and rigour principles and guidance, particularly that outlined by Yardley $(2000,2015)$ of sensitivity to research context, commitment and rigour, transparency and coherence, and impact and importance.

\section{Findings}

We constructed seven main themes, each capturing several subthemes: (1) Heightened emotionality; (2) feelings of change, loss, and uncertainty; (3) recognising the value of self-care; (4) efforts to think positively; (5) opportunities for relief, growth, and development; (6) the importance of togetherness; and (7) frustration with government and media. Figure 1 presents these seven themes alongside their associated subthemes. This section details and explores these themes, drawing on participants quotes to illustrate and evidence the aspects discussed.

We note for the reader at this stage that our themes aim to capture a complex picture. Our participants' accounts were multifaceted, and seemingly contradictory experiences were sometimes present both within and across accounts. In developing and presenting themes, we have sought to acknowledge and explore these complexities, consistent with guidance for rigorous qualitative analysis and reporting (Braun \& Clarke, 2006; Yardley, 2000, 2015). To indicate reoccurrence of a given aspect in presenting themes, we use: "almost all" participants where a finding is present for 80 or more of the 109 accounts; "the majority" for 55-79 accounts; "many" participants for 26-54 accounts, and "some" where a finding is connected to 25 or fewer accounts. This is for transparency, rather than indicating salience, as within reflexive thematic analysis a finding can be meaningful based on its importance for even a few participants (Braun \& Clarke, 2006).

\section{Theme 1: Experiences of heightened emotionality}

The majority of participants described intense, difficult feelings, commonly including sadness, anxiety and worry, anger, frustration, dread, and helplessness; "I have felt angry, sad and had times of bad depression and anxiety throughout the lockdown"; "I occasionally feel helpless, stressed and slightly frustrated". Some described irritability, often increasingly so: "lockdown has begun to take its toll and I'm becoming agitated and upset at the smallest things." However, some described drained and detached at times: "I feel so anxious and emotional and simply choose not to think about it, becoming sort of numb again [...] I have felt the last couple of months have been a blur and have felt so disassociated from reality."

Participants' emotional state seemed to shift often. Some describing mood swings: "I would say that lockdown will have me feeling extremely numb one minute and extremely tense the next." Some noted shifts over time, saying they felt okay initially but their mood declined, or vice versa; "in the beginning weeks of lockdown it wasn't too bad as there was a belief that it wouldn't last over summer, however [...] with nothing to look forward to it is very difficult to maintain a positive attitude."

Participants attributed feelings to various factors, including feeling overwhelmed, feeling trapped within their households, missing people, cancellation of examinations, and uncertainty about the future. Some noted specific circumstances, such as existing mental health difficulties, household conflict, having or living with people with health conditions, and social anxiety; "my moods have been a lot worse since lockdown with depression and an eating disorder getting even worse"; "there was a lot of conflict at first as residing in a place that has caused everyone a lot of pain tends to bring up past feelings." However, some struggled to understand why they felt the way they did: "I remember at the start of lockdown feeling inexplicably angry. I am not usually an angry person so this confused me." Some said they had begun overthinking and ruminating, which was difficult: "this situation caused me to overthink everything and gave me more time to be anxious about details that would not even cross my mind during normal time."

Many reported worries about COVID-19. Some expressed fear for themselves, particularly for those with health conditions: "I am in a high risk category and have felt really anxious about getting COVID-19 as it would most likely make me really ill and possibly kill me." There was fear for loved ones, often for 
those who were vulnerable, and of transmitting COVID themselves; for instance, "I was terrified of anyone that I knew getting it, especially my sister who suffers from asthma."

However, some participants often described more positive feelings. For many these occurred alongside difficult feelings; "I have found that during lockdown, there are days where I experience peace and happiness but other days where I want to break down and cry." Some reflected that overall, they mostly felt okay: "there has been mixed feelings when in lockdown from being happy to feeling a bit down and stressed but overall it hasn't been bad!"

\section{Theme 2: Feelings of change, loss, and uncertainty}

Many highlighted substantial change to daily life: "nothing has really stayed the same since lockdown began." They described specific changes, including moving back in with their family, parents working at home, and being unable to freely go out. Many noted the change to their daily routine: "the major thing since lockdown is not doing a lot, now there is no school or exams, I have no structure to my day." Many described lockdown as boring, with days blurring together:

It feels less like there has been any great change and more like everything is just stagnant. Within lockdown, the days just sort of run on to each other and it feels like everything has just paused, this ultimately has led to a slight dread, feeling like l'm missing out on life in some way.

Almost all participants shared feelings of loss. This included loss of specific experiences, such as travelling, employment and work experience opportunities, loss of learning resources familiar studying experiences and environment: "I also unfortunately lost a job that took a significant amount of training to get which was disappointing"; "I was meant to have my final semester of my first year at university, party a lot and then travel for the summer before I return to university again."

Many participants highlighted losses that seemed to represent normative teenage "rites of passage", including prom, the last day of school, starting university, learning to drive, travelling, and spending time with friends; "I feel a sense of missing out (travelling with friends in the summer, freshers week, making friends, moving in) even though I know we are all in the same position."; "I missed out on a proper ending to school, my exams that I worked so hard for, all the traditions I had anticipated over the last five years just taken from me so quickly!" Cancellation of examinations were also perceived as a loss, with many participants feeling less in control and like they had wasted time: "When it was announced that GCSEs were cancelled, I was distraught. [...] It felt like all of my efforts had gone to waste and I would never get back all the time I had spent or 'wasted' revising".

Many described broader feelings of loss. Some outlined loss of freedom and independence; "not being able to do what I want or go where I want is something I've been struggling with." It sometimes seemed to be the conceptual loss of freedom that was difficult; "I do wish I had the opportunity to do things, even though I wouldn't have done them anyway." Some described loss of purpose and motivation now they did not have daily goals and/or formal education settings: "I often find myself refusing to get out of bed in the mornings because there doesn't seem to be any point." For others, it was the loss of relationships, with some reporting feeling more distant from those outside their households, or that relationships were weakening: "my friendships are now more distant as it's harder to keep up with people as there's nothing to talk about and also a lot of people have lost motivation to want to talk."

A small number of participants disclosed a family bereavement. These participants described having to sit separately from family at funerals or not being able to attend at all: "not being able to go to [my grandad's] funeral was extremely hard and upsetting."

The majority of participants described feeling uncertain about the future, particularly around educational and vocational possibilities. Cancellation of examinations and lack of clarity around alternative grading was frequently commented on here. Many noted that this brought new uncertainty about grades and the future, including that grades wouldn't be taken seriously "because it seems like we 'haven't earned it"', and there were fears about the long-term impact:

I can't even sit an exam to determine a [university] place, nobody seems to understand how the teachers will rank us so I can't plan what uni I'll be doing to, whether or not I will be able to move out, whether or not I should take a year out etc. and being unable to make a plan means there's no way I can make myself feel in control of my situation.

Vocationally, many felt lost opportunities (e.g., work experience) could impact their chances in next steps; "I cannot get work experience in the NHS [National Health Service], as I want to do physiotherapy, and I'm worrying about it all the time." Some highlighted feelings of uncertainty about what university and college would be like moving forward and the economic impact of the pandemic created uncertainty: "I'm also fearful of job opportunities in the future due to the spiralling economy."

Though participants' feelings of uncertainty was often focused on such educational and vocational trajectories, there were also broader concerns and a wider overall sense of increased unpredictability moving forward:

I'm also worried in general about what the future of the world might look like, and how long things will take to go back to normal. Will my young adult years have to be spent socially distancing? Thinking about this too much quickly makes me feel quite depressed so I try not to.

\section{Theme 3: Recognising the value of self-care}

Participants tended to emphasise the value of self-care in lockdown, and often described a range of self-care strategies; however, this didn't mean selfcare was easy for everyone. Many described how hobbies and activities helped them to relax and feel better, such as baking, drawing, exercising and eating healthily, being outdoors, learning new things, and spending time with pets. Participants highlighted how such activities helped them keep busy and pass the 
time, and could distract them from difficult feelings: "if I didn't keep myself busy with the baby [younger sibling], films or sketching I would allow the loneliness to consume me."

Many described developing routine and structure for themselves and creating goals; "one thing that is helping with my wellbeing during lockdown is having a routine in place, as it allows me to keep busy and stops me from getting anxious and worried." However, such approaches could feel pressurising for some, and some noted the need for self-compassion: "we are going through a major crisis globally, we have to cut ourselves some slack."

Although participants recognised self-care as important, some found it difficult: "lockdown has also caused me to start unhealthy habits such as not doing any exercise, oversleeping, and generally not looking after my own physical and mental health anymore." Some described strategies they saw as helpful and problematic, including smoking and emotion suppression: "I know that it is unhealthy to suppress your emotions and not deal with anxious thoughts but that has been mainly my coping strategy."

\section{Theme 4: Efforts to think positively}

Many talked about adopting a "positive mindset" in lockdown, using various thinking strategies. Some focused on positive aspects of lockdown to compensate for more difficult parts: "I miss my friends, a lot, but take this time to relax and enjoy time with your family." Some participants described trying to accept the situation:

I have had phases where I have been down and upset maybe even a little big angry, but now after a long period I have accepted the fact this is not a normal situation and there is nothing to do to change it.

A small number of participants described suppressing difficult feelings. For some this was presented as a pragmatic decision to stay positive ("instead of moping around feeling sorry about myself I've decided to be productive"), while for others this seemed to constitute avoidance: "I feel so anxious and emotional and simply choose not to think about it, becoming sort of numb again."

Some participants focused on finding things they were grateful for. This included personal circumstances such as supportive relationships, access to outdoor spaces, and limited personal impact in terms of health, finance, or personal risk: "I feel lucky as no one in my family has been affected by COVID-19 so far and I have a supportive family with a big garden and lots of places we can go without the stress of social distancing." Some described feeling well-suited to lockdown, which helped them think about the experience more positively. This was mostly around being comfortable in one's own company, preferring to be at home (including due to difficulties such as social anxiety), and already being used to "long distance" relationships: "when I first heard of lockdown I was quite excited [...] I really don't like going outside. I feel safe inside and no one is going to judge me when I am inside."

Finally, some described hopefulness for a post-lockdown future, focusing on lockdown as temporary: "It is really important that we remind each other that this is only temporary and that the best thing to do is just keep going forward." These participants frequently highlighted things they would appreciate more afterwards, typically spending time with loved ones: "lockdown has just made me look forward to planning and doing more things with the people I care about." However, some said this hope was fading over time: "In the beginning weeks of lockdown it wasn't too bad [... now] it seems inevitable it will last until the end of the year with little hope for the future."

\section{Theme 5: Opportunities for relief, growth, and development}

The majority of participants noted positive opportunity within lockdown. Many described relief from "normal" life. This included academic relief, such as being able to work independently and cancellation of examinations: "the thing I like about quarantine is that I can do my work at my own pace"; "not having to take my exams [...] took a huge stress off me". Participants also noted relief from social pressures, with less concern about fitting in or being judged: "no pressure to [...] wear the right thing or say the right thing".

Many reflected that having this much time and space offered novel opportunities for self-exploration and personal development. This included selfreflection, evaluating what they wanted from life, and considering what they might change: "lockdown is looking like a time for self-reflection on the past and things I am doing right and wrong." Some explored new hobbies (or revisited old ones), or learned new skills: "I am taking the opportunity to learn new skills such as gardening, baking, pointing a patio, cutting and pruning hedges, and vehicle maintenance." However, this emphasis on personal growth could itself be pressurising:

Just because your friend has perfected her baking or learnt a new instrument doesn't mean you should hold yourself to the same standard or feel pressure to have learnt a new skill, maybe just take a break and go easy on yourself because we're in a really stressful situation.

Finally, many highlighted that lockdown had enabled them to strengthen and appreciate their relationships and wider community. Often this was within their household, as they were spending quality time together and supporting one another: "as a family, I think this time together and what is going on has made us appreciate each other so much more." Some described feeling closer to those outside their household and appreciating friendships more: "I actually think that I have gotten closer [to friends] as I haven't had much time to do anything else other than talking to friends".

\section{Theme 6: The importance of togetherness}

Almost all participants placed strong emphasis on staying connected to other people during lockdown. The majority noted the value of positive relationships with family and friends, which they said made lockdown easier to cope with. Many wrote about spending more quality time than usual with others in their households, and even talking to those outside their households more, which they enjoyed; "I enjoy spending time with my family as we are all very close anyway and this is the first time in a long while we have all been able to spend time together." Many participants highlighted that relationships with 
people who were supportive and understanding was important for wellbeing; "sometimes the feeling of abnormality and uncertainty has upset me or put me in a bad mood but my girlfriend and I have helped each other though those moments." Many described trying to reach out and stay connected with those outside their households via technology, and often encouraged other teenagers to do the same; "every Friday, I FaceTime my friends and we all drink some wine and talk about anything."

However, simultaneously to the above, almost all participants described feeling socially disconnected in some way. Some experienced issues with feeling connected in their households. This was due to a general sense of tension within the house (e.g., "[my] family gets into trivial disputes easily because conversations are frequently repeated, and lifestyle habits clash") or due to difficult relationships with members of their household: "I sometimes feel alone because my relationship with my mum's husband is pretty strained. I don't speak to him and try to avoid him so that can lead me to isolate myself in my room."

Beyond their households, the majority of participants described missing people and feeling isolated and distant from friends and family. Some felt unable to reach out to others, or found it hard to stay meaningfully connected; "lockdown has made it harder to stay in contact with as many people and it makes me feel so heavy at times, I really miss people but l'm not close enough to just reach out." Many reflected that remote forms of social interaction (e.g., texts, phoning, video calls, and social media) was difficult to maintain or was not the same as being face-to-face:

Phoning or texting is difficult sometimes so now that's the only way to talk to people, I talk less to them and it makes me feel quite sad and it isn't the same anyway. I miss seeing people and being able to hug and just be near them.

These feelings of disconnect were often a source of difficult feelings, and some experienced loneliness: "I have felt incredibly lonely despite having what is honestly a great support system."

However, many participants described a feeling of being "all in this together." They described how the pandemic and lockdown had created a sense of community, which seemed to extend to their local neighbourhood, the country, or even the world; "people on my street that l've never spoken to before are now interacting with the rest of the neighbourhood which is quite weird, in a nice way." Shared experiences like clapping for the NHS seemed to contribute to this: "the NHS clap, every Thursday, puts a smile on my face and makes me realise that we're all in this together." For some, this broader connectedness seemed helpful in rationalising losses, as they framed them as meaningful sacrifices; "it is stressful not being able to go out, however that it is a small sacrifice to pay." However, some expressed considerable frustration with those breaking lockdown restrictions, highlighting that this would have negative implications for everyone else:

I'm constantly frustrated by the people that don't care about the situation, don't listen to the government rules and act like they don't care. I'm angry and sad because I know that because of them we might risk seeing friends again or have one normal month this summer.

\section{Theme 7: Frustration with government and media}

Some participants expressed frustration towards the UK government and the news media. In relation to the government, these participants said they felt the pandemic was being poorly handled, with concerns that lockdown was being eased too soon (note time of data generation was May 2020 , when initial restrictions were first beginning to be eased), and that guidance and communication about restrictions was confusing, which sometimes caused conflict: "I go for a walk with a friend however come back to face confrontation with my brother as he believes that to be unsafe. If we were given clearer guidance, then these disputes could be avoided." A small number of participants did not agree with lockdown restrictions: "the way lockdown was imposed and handled has been a great violation of my right to freedom."

Participants also noted that they were unsure the government would effectively make educational settings safe: "I am unsure if I want to go back in September because l'm unsure that the government has the best supervisions." They also raised concerns about how much guidance had been offered for their age group, particularly around understanding approaches to cancelled or forthcoming examinations and ensuring limited impact of lost educational experiences:

Year 12 (my year) have already missed 2 months of education and will go on longer and we still have to do our A levels. The information we are receiving is not clear and practically non-existent when it comes to sixth forms. [footnote: these examinations were later cancelled]

Some also highlighted frustration with media, particularly news media, explaining that it was often distressing: "it is filled with contradicting, unpleasant information and isn't good for mental health." Some expressed irritation with how negative the news coverage was, which they felt was irresponsible: "The news channels have been extremely helpful in depressing the country even further by primarily focusing on every negative possible during this pandemic instead of attempting to lift our moods or at least mention some form of positivity." A few participants said they had begun limiting their engagement with the news for the benefit of their wellbeing: "I've recently stopped watching the news because that wasn't helping me at all, seeing all those numbers of people that unfortunately passed away or have got it is honestly heart-breaking."

\section{Discussion}

We set out to qualitatively explore older adolescents' subjective experiences of the initial UK COVID-19 lockdown, with an emphasis on how they understood their lockdown experiences, perceptions of impact, and experiences and management of wellbeing. Our findings identified seven themes, which collectively capture how lockdown could be an intense, uneasy experience for older adolescents, with difficult emotions, feelings of loss and uncertainty, lack of connection, and concerns about wider societal systems and decisions relating to the pandemic. Yet, findings also suggest a level of adaptation and resilience in the face of lockdown, with many adolescents undertaking considerable efforts to actively cope, and maintain relationships, and even experiencing relief and 
identifying opportunity for growth. These findings capture a multifaceted experience for adolescents in the initial lockdown, participants tended to describe experiencing both unease and more positive aspects of lockdown. Here, we explore these key aspects of our findings in turn, drawing pluralistically on relevant theory and evidence and considering the implications throughout.

\section{Psychological distress in lockdown}

Participants' descriptions of lockdown as an "emotional rollercoaster" highlight the depth and intensity of the emotional impact for this group. This echoes other recent qualitative findings around emotional impact (Ashworth et al., 2021; Branquinho et al., 2020) and reflects emerging evidence of worsening adolescent mental health and wellbeing (Pierce et al., 2020). Notably, the loss of routine, normality, psychological control, independence, purpose, and aspects of social connection that older adolescents experienced, alongside fear about COVID-19 and the future, represent a sudden, profound life disruption. Thus, participants' feelings are arguably normative reactions, and it would be surprising not to see an emotional response to such intense changes; indeed, others have challenged the pathologizing of such reactions as a youth mental health 'crisis' (Danese \& Smith, 2020; Siddaway, 2020). Though such distress and anxiety could ordinarily be conceptualised as emotional symptoms, it must be considered that adolescents' emotional reactions have been normal under the circumstances, and may prove temporary (Danese \& Smith, 2020; Siddaway, 2020). As the pandemic continues, opportunities for older adolescents to engage in emotional reflection will be valuable, alongside support in developing coping and emotion regulation strategies. Findings highlight that the extent of distress varies across individuals and time, highlighting the need for varied provision options to meet these diverse needs and ongoing monitoring and exploration of adolescent emotional wellbeing and mental health over time.

Findings demonstrate that older adolescents have grieved lost rites of passage and day-to-day teenage experiences. Though many rationalised these as sacrifices, perhaps reflecting the UK Government's initial lockdown morality discourse and sacrificial coding of public behaviour (Morgan, 2020), losses were nevertheless felt acutely. Some have questioned whether pandemic measures have been unnecessarily costly for UK youth during an important stage of development (Efuribe et al., 2020; Gruber et al., 2020), and our findings suggest, at least to some degree, that this may be the case. Though long-term implications are beyond our remit, these feelings of distress at such disruption highlight the need to consider adolescents' needs and preserve a sense of normality within ongoing restrictions. Public messaging acknowledging or even celebrating adolescents' efforts and demonstrating attention to their ongoing needs may be beneficial both during and after the pandemic, given their belief that they have made important short- and long-term personal sacrifices for society. This is perhaps particularly important as our participants felt overlooked by the government, and in light of blame messaging towards UK youth for rising cases, criticized elsewhere as unfair and divisive (Reicher, 2020).

Participants described considerable loss of control and freedom alongside feelings of helplessness, both presently and regarding their futures. Locus of control, or the extent to which people perceive control over events in their lives, shows associations with wellbeing and mental health (Flores et al., 2020; Groth et al., 2019), and evidence suggests a highly external locus of control (when control is perceived as the "result of chance, fate, as under the control of powerful others, or as unpredictable because of the greater complexity of forces surrounding [them]" (Rotter, 1966; p.1) increases the likelihood of emotional difficulties among adolescents (Flores et al., 2020), especially alongside high levels of stress (Huebner et al., 2001). It therefore follows that the loss of control that older adolescents experienced during the lockdown, coupled with a complex and stressful situation, uncertain futures, and plans dictated by powerful others such as the government, raised difficult feelings. Findings emphasise that shared decision-making, alongside clear justification and transparency in decisions, may be especially vital as we emerge from the pandemic and respond to ongoing consequences, to help reinstate perceived autonomy and control for adolescents, across all domains of adolescents' lives. Furthermore, as emerging evidence suggests young adults are disproportionately affected by ongoing pandemicrelated UK employment issues (Boneva et al., 2020; Francis-Devine et al., 2020), ongoing recovery initiatives relating to this for young people may not only provide vocational and economic benefits but also wellbeing benefits, giving adolescents greater confidence in planning next steps.

Of course, a novel fear was COVID-19 itself, and many participants expressed worry that they or a loved one would contract the virus, particularly when they had a high-risk health condition. This offers further evidence that COVID-19 anxiety is likely acute for those more vulnerable to the impact of the virus (Alonzi et al., 2020; Holmes et al., 2020), and illuminates concerns among adolescents about vulnerable family members, as also noted by Ashworth et al. with younger adolescents (Ashworth et al., 2021). Findings highlight the need for support for adolescents who are at greater risk or have loved ones at risk, and monitoring of mental health trends should be attentive to such circumstances. Findings also contribute qualitative evidence of the distress and anxiety that media coverage of the pandemic could prompt for older adolescents in the UK. Initial global media framing of COVID-19 has been driven by fear messages, scaremongering, and 'breaking news' coverage (Ogbodo et al., 2020), and research demonstrates that risk-elevating messages in infectious disease coverage intensifies public anxiety (Sell et al., 2017); such reporting may explain the distress noted by our participants. Researchers could explore "healthy" balances of media engagement at this time, particularly for different age groups. Notably, some expressed desire for positive coverage that could offset anxiety-inducing coverage and messaging; while messages of hope have been somewhat present in UK media coverage (Ogbodo et al., 2020), findings perhaps suggest need for greater emphasis on de-escalating fear and anxiety and messages of hope as the pandemic continues across the UK and other countries.

\section{Adaptation and Growth in Lockdown}

Findings offer insight into the adaptation and resilience occurring among adolescents in the first UK lockdown, with the majority placing value on looking after their wellbeing. For those who found that their usual coping strategies were incompatible with restrictions, they described actively working to identify new and feasible approaches to self-care. As a whole, participants adopted various strategies to help with their wellbeing during lockdown, including both active coping strategies, such as seeking support from their friends, and internal cognitive coping strategies, such as finding the positives of lockdown. This is unsurprising given that such coping strategies are among the most frequent used by adolescents to cope with everyday stressors (Cicognani, 2011; Gelhaar et al., 2007; Stapley et al., 2020). However, many reported strategies that could be perceived as avoidance, such as using distraction techniques and suppressing their feelings. Although this is a technique used more often by younger adolescents (Escenbeck et al., 2018), perceived lack of control in lockdown may have meant this seemed the only available strategy. While avoidance strategies have been framed as 'maladaptive', research suggests that techniques like distraction are 
not necessarily avoidant if the individual first acknowledges the stressor (Compas et al., 2001), as participants often described here. Indeed, a recent study from Dewa et al. (Dewa et al., 2021) identified that young people's use of distraction coping strategies in the pandemic were not linked with poor mental health, although other dysfunctional coping strategies (e.g., substance misuse) were. In the face of quarantine situations and restrictions as well as in responding to the aftermath of the COVID-19 pandemic, provision of information around coping alongside active discussion with adolescents to encourage individualised reflection to identify appropriate coping strategies will be valuable (Raccanello et al., 2020).

Findings suggest that lockdown also brought considerable relief for older adolescents. That such a situation - even with the psychological distress it often brought- was somewhat preferable to "normal" day-to-day adolescent life is worrying. Concern about the demands of the UK education system on adolescents are not new, including the growing emphasis on performance and high stakes exams (Joanne Banks \& Smyth, 2015; Hutchings, 2015), and it is well-documented that adolescents face social demands that can be stressful (Blakemore, 2018, 2019; Sumter et al., 2009). Participants' responses to UK school and university closures in 2020 offer unique insight into the extent of this pressure and stress and the personal impact it can have, as well as into adolescents' use of their time when demands are lessened. Participants' engagement in personal development and evaluation of life in lockdown reflects positive youth development positioning of adolescents as agents of their own development and growth (Larson, 2006), and it has previously been argued that educational systems are at odds with the adolescent need for self-determination and autonomy (Eccles et al., 1993). The COVID-19 pandemic may represent an opportunity to critically reflect on the structure of our education system and the demands placed on our adolescents, and the extent to which we act as facilitators in self-exploratory adolescent development. Such reflection should include active discussion with adolescents at both a local and national level about what can be learned and acted on to carry forward learning from this time.

\section{(Dis)Connection}

Findings offer new insights into the value adolescents place on social connectedness during lockdown periods. Participants indicated that positive, close relationships (both in and beyond their households) made the initial lockdown more positive and provided a source of support. This is unsurprising given the developmental timing of lockdown during a period where social relationships, particularly with peers, are highly valued (Greca et al., 2010; Umberson et al., 2010). Other recent studies have similarly found that quality social connection in the context of lockdown is valuable for aspects of coping and wellbeing (e.g., Bu et al., 2020; Dewa et al., 2021). Our findings extend knowledge by highlighting efforts made by older adolescents to stay connected. Interestingly, some noted greater depth and quality in their relationships. Findings suggest there is value in supporting adolescents in staying meaningfully connected during periods of enforced social isolation, particularly as it seems this was not always easy, as discussed below. Furthermore, it may be beneficial to consider ways to strengthen knowledge and skills around wellbeing and coping among parents/carers and adolescents themselves, to facilitate effective, quality family support for adolescents given their tendency to turn to informal others as part of coping (Raccanello et al., 2020; Rickwood et al., 2005). Findings also highlight the value that adolescents placed on being "all in this together", as similarly reported by Dewa et al. (2021). A sense of community and shared experiences appeared to be personally meaningful in managing restrictions and other perceived sacrifices, suggesting that public messaging promoting solidarity may be valuable for participants' wellbeing in the face of continued disruption, and perhaps even for adherence to ongoing restrictions.

However, alongside this was a strong feeling of disconnection, with participants finding it difficult to reach out and relationships becoming more distant. Commentary around remote connectedness not being the same as in-person interaction demonstrates that remote connection can recoup some of the social losses in lockdown but falls short of fully replicating offline connections, reflecting understandings that online and offline communication offer distinct functions for adolescents' close relationships (Nesi et al., 2020). Such disconnection is at odds with the typical developmental emphasis on social ties in adolescence. Indeed, research has demonstrated that feeling socially isolated in adolescence can show associations with worsened mental health (Hall-Lande et al., 2007), and evidence suggests that periods of social isolation and disruption to social bonds in adolescence can have both psychological and physical health consequences (Cruz et al., 2016). Thus, our study illuminates the variability and barriers as to the level and quality of connection and support in lockdown, with some experiencing more acute isolation, and provides further support for an emphasis on social (re)connection in the aftermath of UK restrictions. It will be valuable to consider ways to support adolescents in rebuilding social connections and, for some, social skills, providing opportunities to socialise and spend time with peers within education and community settings. This may be at odds with a growing emphasis on "catching up" academically, but ought to be treated as a critical priority to avoid further disconnection during a key social developmental period.

\section{Strengths and Limitations}

At the time of writing, this study is one of few qualitative empirical studies that has explored adolescents' experiences of the COVID-19 UK lockdown; indeed, qualitative research as a whole has been underused in the UK mental health response to the pandemic (Demkowicz et al., 2021). An emphasis on this age group's voices is key in ensuring we can build a meaningful understanding of their experience. Our use of inductive data generation and analysis is a key strength of the study in this respect. Our open-ended approach to data generation, wherein participants were able to focus on what was personally meaningful to them and prompts were neutral and open, facilitated development of a dataset that more authentically captures adolescents' own perspectives on their experiences. An inductive analytic approach enabled us to work "bottom-up" from these perspectives and in doing so construct findings that sought to best capture and articulate these experiences without being driven by preconceptions. In turn, pragmatically making sense of these findings by drawing on blended theoretical and conceptual perspectives allowed a deeper understanding of the varied aspects explored within the study.

The online tool used for data generation allowed participants to reflect in their own time, with perhaps less perceived pressure (Braun et al., 2020), and our open-ended approach allowed participants to focus upon aspects of greatest personal salience. However, anonymous online data generation meant that we were unable to clarify meaning or follow up on specific points. Our emphasis on participants' own perspectives here means that there were limitations to our remit and learning; for instance, this approach means we cannot determine the appropriateness or efficacy of participants' coping strategies (though some did highlight limitations of their approaches) and findings reflect conscious coping, as it has previously been suggested that individuals engage in some 
involuntary coping not within their conscious awareness (Connor-Smith et al., 2000). Furthermore, a single timepoint for data generation may mean that accounts could to some extent reflect participants' mood at the time of writing, particularly as participants noted that their feelings and mood could fluctuate.

We note limitations in sample representativeness. Firstly, our sampling operated broadly via organisations, networks, and social media, with participants volunteering to take part. Thus, our sample represents individuals who felt comfortable and interested in sharing subjective experiences at this time, perhaps meaning that those with acutely challenging lockdown circumstances or difficulty reflecting on feelings may have been less likely to participate. Our written data generation method may have been off-putting for some, such as those with difficulty communicating in writing, although consistent with guidance we offered reassurance that spelling and grammar were unimportant (Braun et al., 2020). Indeed, some groups appeared more likely to participate; most participants were girls and young women and all participants were in education. Readers should be mindful of such imbalances, and future research should seek to achieve representativeness as well as exploring specific adolescent sub-populations' experiences of lockdown (e.g., those not in education, employment, or training), and should adopt varied methods of data generation.

\section{Conclusions}

Our study offers rich insight into the complex and multifaceted nature of older adolescents' subjective experiences of the first UK lockdown, with individuals experiencing both unease and growth in response to these circumstances. Findings offer insights and implications that offer value for supporting adolescents as the UK (at the time of writing) works towards reducing and eventually eradicating lockdown restrictions. This includes provision of support directly in relation to wellbeing and mental health, within their social networks and relationships, and more broadly in helping adolescents make sense of and respond to health information and public messaging. Implications are not restricted purely to current restrictions, however, and offer relevance in implementing support for adolescents as the aftermath of the pandemic continues, such as how ongoing employment issues may prove challenging for adolescents' and young people's wellbeing. Findings also offer wider implications beyond the UK for countries still experiencing high levels of restrictions relating to the pandemic and can be valuable in future instances of quarantine situations and pandemic-related disruptions. More generally, findings also highlight that the pandemic could represent a unique opportunity to take stock and consult with adolescents about what "adolescence" and their daily lives ought to encompass, given that the unease that lockdown brought co-existed alongside feelings of relief and the capacity for personal growth. Further investigation is needed to more fully understand the varied complexities in adolescents' experiences of lockdown(s), including exploring how reactions have shifted across the course of the pandemic and its aftermath, and to explore the ways in which effective support can be offered at this time and in future emergency and isolation situations.

\section{Abbreviations}

A Level

General Certificate of Education Advanced Level

COVID-19

novel coronavirus disease 2019

GCSE

General Certificate of Secondary Education

$\mathrm{NHS}$

National Health Service

TELL

Teenagers' Experiences of Life in Lockdown

UK

United Kingdom

\section{Declarations}

\section{Ethics approval and consent to participate/consent for publication}

Ethics approval was granted by The University of Manchester Ethics Committee (Ref: 2020-9615-15277). Participants confirmed consent their take part via the online portal prior to providing any data, including consent for publication of their data within written reports.

\section{Availability of data and materials}

The dataset generated and analysed in the current study is not publicly available due to ethical restrictions.

\section{Competing interests}

The authors declare that they have no competing interests.

\section{Funding}

This study is partially funded by the Economic and Social Research Council's Impact Acceleration Account at The University of Manchester.

\section{Authors' contributions}


Demkowicz (Principal Investigator) and Ashworth (Co-Investigator) led the conception and design of the current study, the analysis of data, and development of the manuscript. O'Neill was a major contributor to the analysis of data and to the writing of the manuscript. Hanley was a major contributor to the study design, the translation of findings into implications, and reviewing and refining the manuscript. Pert made contributions to the analytical process and contributed to reviewing and refining the manuscript. All authors read and approved the final manuscript.

\section{Acknowledgements}

Thanks are due to our participants, for sharing their experiences and insights with us. We are also grateful to Claire Briegel for reviewing our findings at an earlier stage and offering valuable questions for further consideration, to Tee McCaldin for continued discussion and insights during the shaping of this study, to Cathy Creswell for offering reflections on the practical implications of findings for those supporting adolescents during the pandemic, and to Neil Humphrey for consistently championing this project and for offering guidance in refining the manuscript.

\section{References}

Alonzi, S., La Torre, A., \& Silverstein, M. W. (2020). The psychological impact of preexisting mental and physical health conditions during the COVID-19 pandemic. Psychological Trauma: Theory, Research, Practice, and Policy, 12, 236-238. https://doi.org/10.1037/tra0000840

American Psychological Association. (2018). APA Style Journal Article Reporting Standards: Information recommended for inclusion in manuscripts that report primary qualitative research. https://apastyle.apa.org/jars/qual-table-1.pdf

Ashworth, E., Hunt, A., Chopra, J., Eames, C., Putwain, D. W., Duffy, K., Kirkby, F., McLoughlin, S., \& Saini, P. (2021). Adolescents'lockdown-induced coping experiences (ALICE) study: A qualitative exploration of early adolescents' experiences of lockdown and reintegration.

Banks, James, \& Xu, X. (2020). The mental health effects of the first two months of lockdown and social distancing during the Covid-19 pandemic in the UK. Institute for Fiscal Studies. https://www.ifs.org.uk/publications/14874

Banks, Joanne, \& Smyth, E. (2015). 'Your whole life depends on it': academic stress and high-stakes testing in Ireland. Journal of Youth Studies, 18(5), 598616. https://doi.org/10.1080/13676261.2014.992317

Blakemore, S. J. (2018). Avoiding social risk in adolescence. Current Directions in Psychological Science, 27, 116-122.

https://doi.org/10.1177/0963721417738144

Blakemore, S. J. (2019). Adolescence and mental health. The Lancet, 393(10185), 2030-2031. https://doi.org/10.1016/S0140-6736(19)31013-X

Boneva, T., Golin, M., \& Rauh, C. (2020). Inequality in the impact of the coronavirus shock: New survey evidence for the UK. Journal of Public Economics. https://doi.org/10.1016/j.jpubeco.2020.104245

Bouchard, K. (2016). Anonymity as a double-edge sword: reflecting on the implications of online qualitative research in studying sensitive topics. Qualitative Report, 21(1), 59-67.

Branquinho, C., Kelly, C., Arevalo, L. C., Santos, A., \& Gaspar de Matos, M. (2020). "Hey, we also have something to say": a qualitative study of Portuguese adolescents' and young people's experiences under COVID-19. Journal of Community Psychology, 48(8), 2740-2752. https://doi.org/10.1002/jcop.22453

Braun, V., \& Clarke, V. (2006). Using thematic analysis in psychology. Qualitative Research in Psychology, 3, 77-101.

Braun, V., Clarke, V., Boulton, E., Davey, L., \& McEvoy, C. (2020). The online survey as a qualitative research tool. International Journal of Social Research Methodology. https://doi.org/10.1080/13645579.2020.1805550

Bu, F., Steptoe, A., \& Fancourt, D. (2020). Loneliness during a strict lockdown: trajectories and predictors during the COVID-19 pandemic in 38,217 United Kingdom adults. Social Science and Medicine, 265(November), 113521. https://doi.org/10.1016/j.socscimed.2020.113521

Castagnoli, R., Votto, M., Licari, A., Brambilla, I., Bruno, R., Perlini, S., Rovida, F., Baldanti, F., \& Marseglia, G. L. (2020). Severe Acute Respiratory Syndrome coronavirus 2 (SARS-CoV-2) infection in children and adolescents: a systematic review. JAMA Pediatrics, 2(9), 882-889.

https://doi.org/10.1001/jamapediatrics.2020.1467

Chen, F., Zheng, D., Liu, J., Gong, Y., Guan, Z., \& Lou, D. (2020). Depression and anxiety among adolescents during COVID-19: a cross-sectional study. Brain, Behavior, and Immunity, 88, 36-38. https://doi.org/10.1016/j.bbi.2020.05.061

Cicognani, E. (2011). Coping strategies With minor stressors in adolescence: relationships with social support, self-efficacy, and psychological well-being. Journal of Applied Social Psychology, 41(3), 559-578. https://doi.org/10.1111/j.1559-1816.2011.00726.x

Clemens, V., Deschamps, P., Fegert, J. M., Anagnostopoulos, D., Bailey, S., Doyle, M., Eliez, S., Hansen, A. S., Hebebrand, J., Hillegers, M., Jacobs, B., Karwautz, A., Kiss, E., Kotsis, K., Kumperscak, H. G., Pejovic-Milovancevic, M., Christensen, A. M. R., Raynaud, J. P., Westerinen, H., \& Visnapuu-Bernadt, P. (2020). Potential effects of "social" distancing measures and school lockdown on child and adolescent mental health. European Child and Adolescent Psychiatry, 29(6), 739742. https://doi.org/10.1007/s00787-020-01549-w 
Compas, B. E., Connor-Smith, J. K., Saltzman, H., Thomsen, A. H., \& Wadsworth, M. E. (2001). Coping with stress during childhood and adolescence: problems, progress, and potential in theory and research. Psychological Bulletin, 127, 87-127. https://doi.org/10.1037/0033-2909.127.1.87

Connor-Smith, J. K., Compas, B. E., Wadsworth, M. E., Thomsen, A. H., \& Saltzman, H. (2000). Responses to stress in adolescence: measurement of coping and involuntary stress responses. Journal of Consulting and Clinical Psychology, 68(6), 976-992. https://doi.org/10.1037/0022-006X.68.6.976

Crawley, E., Loades, M., Feder, G., Logan, S., Redwood, S., \& Macleod, J. (2020). Wider collateral damage to children in the UK because of the social distancing measures designed to reduce the impact of COVID-19 in adults. BMJ Paediatrics Open, 4, e000701. https://doi.org/10.1136/bmjpo-2020-000701

Cruz, F. C., Duarte, J. O., Leão, R. M., Hummel, L. F. V., Planeta, C. S., \& Crestani, C. C. (2016). Adolescent vulnerability to cardiovascular consequences of chronic social stress: immediate and long-term effects of social isolation during adolescence. Developmental Neurobiology, 76(1), 34-46.

https://doi.org/10.1002/dneu.22297

Danese, A., \& Smith, P. (2020). Debate: Recognising and responding to the mental health needs of young people in the era of COVID-19. Child and Adolescent Mental Health, 25(3), 169-170. https://doi.org/10.1111/camh.12414

Demkowicz, O., Panayiotou, M., Parsons, S., Feltham, A., Arseneault, L., Ingram, B., Patalay, P., Edge, D., Pierce, M., Creswell, C., Victor, C., O'Connor, R. C., \& Qualter, P. (2021). Looking back to move forward: Reflections on the strengths and challenges of the COVID-19 UK mental health research response. Frontiers in Psychiatry. https://doi.org/10.3389/fpsyt.2021.622562

Department for Education, \& Office for National Statistics. (2019). Schools, pupils and their characteristics: January 2019.

https://assets.publishing.service.gov.uk/government/uploads/system/uploads/attachment_data/file/812539/Schools_Pupils_and_their_Characteristics_2019

Dewa, L. H., Crandell, C., Choong, E., Di Simplicio, M., Nicholls, D., \& Aylin, P. (2021). CCopeY: A mixed-methods coproduced study on the mental health status and coping strategies of young people during COVID-19 UK lockdown. Journal of Adolescent Health. https://doi.org/10.1016/j.jadohealth.2021.01.009

Eccles, J. S., Midgley, C., Wigfield, A., Buchanan, C. M., Reuman, D., Flanagan, C., \& Mac Iver, D. (1993). Developing during adolescence: The impact of stageenvironment fit on young adoloscents' experiences in schools and in families. American Psychologist, 48, 90-101. https://www.apa.org/pubs/journals/amp/

Efuribe, C., Barre-Hemingway, M., Vaghefi, E., \& Suleiman, A. B. (2020). Coping with the COVID-19 crisis: a call for youth engagement and the inclusion of young people in matters that affect their lives. Journal of Adolescent Health, 67(1), 16-17. https://doi.org/10.1016/j.jadohealth.2020.04.009

Escenbeck, H., Schmid, S., Schroder, I., Wasserfall, N., \& Kohlmann, C.-W. (2018). Development of coping strategies from childhood to adolescence: crosssectional and longitudinal trends. European Journal of Health Psychology, 25, 18-30. https://doi.org/10.1027/2512-8442/a000005

Fancourt, D., Steptoe, A., \& Bu, F. (2020). Trajectories of anxiety and depressive symptoms during enforced isolation due to COVID-19: longitudinal analyses of 36,520 adults in England. The Lancet Psychiatry, 8(3), 141-149. https://doi.org/10.1101/2020.06.03.20120923

Flores, J., Caqueo-Urízar, A., Ramírez, C., Arancio, G., \& Cofré, J. P. (2020). Locus of control, self-control, and gender as predictors of internalizing and externalizing problems in children and adolescents in Northern Chile. Frontiers in Psychology. https://doi.org/10.3389/fpsyg.2020.02015

Francis-Devine, B., Powell, A., \& Foley, N. (2020). Briefing paper: coronavirus: impact on the labour market. https://commonslibrary.parliament.uk/researchbriefings/cbp-8898/

Gelhaar, T., Seiffge-Krenke, I., Borge, A., Cicognani, E., Cunha, M., Loncaric, D., Macek, P., Steinhausen, H. C., \& Metzke, C. W. (2007). Adolescent coping with everyday stressors: a seven-nation study of youth from central, eastern, southern, and northern Europe. European Journal of Developmental Psychology, 4(2), 129-156. https://doi.org/10.1080/17405620600831564

Gilleard, A., Lereya, S. T., Tait, N., Edbrooke-childs, J., Deighton, J., \& Cortina, M. A. (2020). Emerging evidence: Coronavirus and children and young people's mental health. https://www.annafreud.org/media/12234/coronavirus-emerging-evidence-3-final.pdf?mc_cid=cdbb8d7349\&mc_eid=5c564bba61

Greca, A. M. La, Harrison, H. M., La, A. M., Moore, H., Adolescent, H., Greca, A. M. La, \& Harrison, H. M. (2010). Adolescent peer relations, friendships, and romantic relationships: Do they predict social anxiety and depression? 4416. https://doi.org/10.1207/s15374424jccp3401

Groth, N., Schnyder, N., Kaess, M., Markovic, A., Rietschel, L., Moser, S., Michel, C., Schultze-Lutter, F., \& Schmidt, S. J. (2019). Coping as a mediator between locus of control, competence beliefs, and mental health: A systematic review and structural equation modelling meta-analysis. Behaviour Research and Therapy, 121(June), 103442. https://doi.org/10.1016/j.brat.2019.103442

Gruber, J., Prinstein, M. J., Clark, L. A., Rottenberg, J., Abramowitz, J. S., Albano, A. M., Aldao, A., Borelli, J. L., Chung, T., Davila, J., Forbes, E. E., Gee, D. G., Hall, G. C. N., Hallion, L. S., Hinshaw, S. P., Hofmann, S. G., Hollon, S. D., Joormann, J., Kazdin, A. E., ... Weinstock, L. M. (2020). Mental Health and Clinical Psychological Science in the Time of COVID-19: Challenges, Opportunities, and a Call to Action. American Psychologist. https://doi.org/10.1037/amp0000707

Hall-Lande, J. A., Eisenberg, M. E., Christenson, S. L., \& Neumark-Sztainer, D. (2007). Social isolation, psychological health, and protective factors in adolescence. Adolescence, 42, 265-286. https://doi.org/10.1130/B26151.1

Holmes, E. A., O'Connor, R. C., Perry, V. H., Tracey, I., Wessely, S., Arseneault, L., Ballard, C., Christensen, H., Cohen Silver, R., Everall, I., Ford, T., John, A., Kabir, T., King, K., Madan, I., Michie, S., Przybylski, A. K., Shafran, R., Sweeney, A., ... Bullmore, E. (2020). Multidisciplinary research priorities for the COVID-19 pandemic:

Page $12 / 15$ 
a call for action for mental health science. The Lancet Psychiatry, 7, 547-560. https://doi.org/10.1016/S2215-0366(20)30168-1

Huebner, E. S., Ash, C., \& Laughlin, J. E. (2001). Life experiences, locus of control and school satisfaction in adolescence. Social Indicators Research, 55(2), 167-183. https://doi.org/10.1023/A:1010939912548

Hutchings, M. (2015). Exam factories? The impact of accountability measures on children and young people. http://www.teachers.org.uk/files/examfactories.pdf

Jones, P. B. (2013). Adult mental health disorders and their age at onset. British Journal of Psychiatry, 202, s5-s10. https://doi.org/10.1192/bjp.bp.112.119164

Kessler, R. C., Berglund, P., Demler, O., Jin, R., Merikangas, K. R., \& Walters, E. E. (2005). Lifetime prevalence and age-of-onset distributions of DSM-IV disorders in the National Comorbidity Survey replication. Arch Gen Psychiatry, 62, 593-602. https://doi.org/10.1001/archpsyc.62.6.593

Kirby, P. (2004). 'A guide to actively involving young people in research: For researchers, research commissioners, and managers'. In INVOLVE support unit.

Kooth. (2020). Week 14: How Covid-19 is affecting the mental health of children and young people. https://xenzone.com/wp-

content/uploads/2020/06/CYP_Infographic_110620-CSE_V5.pdf

Larson, R. (2006). Positive youth development, willful adolescents, and mentoring. Journal of Community Psychology, 34, 677-689.

https://doi.org/10.1002/jcop.20123

Morgan, M. (2020). Why meaning-making matters: the case of the UK Government's COVID-19 response. American Journal of Cultural Sociology, 8(3), 270323. https://doi.org/10.1057/s41290-020-00121-y

Nesi, J., Telzer, E. H., \& Prinstein, M. J. (2020). Adolescent development in the digital media context. Psychological Inquiry, 31(3), $229-234$.

https://doi.org/10.1080/1047840X.2020.1820219

Newby, J. M., O'Moore, K., Tang, S., Christensen, H., \& Faasse, K. (2020). Acute mental health responses during the COVID-19 pandemic in Australia. PLoS ONE, 15 (7 July). https://doi.org/10.1371/journal.pone.0236562

Nowell, L. S., Norris, J. M., White, D. E., \& Moules, N. J. (2017). Thematic analysis: striving to meet the trustworthiness criteria. International Journal of Qualitative Methods, 16(1), 1-13. https://doi.org/10.1177/1609406917733847

NSPCC Learning. (2020). What children are saying to Childline about coronavirus. https://learning.nspcc.org.uk/research-resources/2020/childline-briefingcoronavirus

Ogbodo, J. N., Onwe, E. C., Chukwu, J., Nwasum, C. J., Nwakpu, E. S., Nwankwo, S. U., Nwamini, S., Elem, S., \& Ogbaeja, N. I. (2020). Communicating health crisis: A content analysis of global media framing of COVID-19. Health Promotion Perspectives, 10(3), 257-269. https://doi.org/10.34172/hpp.2020.40

Patton, G. C., Sawyer, S. M., Santelli, J. S., Ross, D. A., Afifi, R., Nicholas, B., Arora, M., Azzopardi, P., Baldwin, W., Bonell, C., Kennedy, E., Mahon, J., Mcgovern, T., Mokdad, A. H., Patel, V., Petroni, S., Reavley, N., Taiwo, K., Waldfogel, J., ... Viner, R. M. (2016). Lancet Commission on Child health. Lancet, 387(10036), 24232478. https://doi.org/10.1016/S0140-6736(16)00579-1.Our

Patton, M. (2015). Qualitative research and evaluation methods (4th ed.). SAGE Publications.

Pierce, M., Hope, H., Ford, T., Hatch, S., Hotopf, M., John, A., Kontopanetlis, E., Webb, R., Wessely, S., McManus, S., \& Abel, K. M. (2020). Mental health before and during the COVID-19 pandemic: a longitudinal probability sample survey of the UK population. The Lancet Psychiatry, 7, 883-892.

https://doi.org/10.1016/S2215-0366(20)30308-4

Raccanello, D., Vicentini, G., Rocca, E., Barnaba, V., Hall, R., \& Burro, R. (2020). Development and early implementation of a public communication campaign to help adults to support children and adolescents to cope with coronavirus-related emotions: a community case study. Frontiers in Psychology, 11(September). https://doi.org/10.3389/fpsyg.2020.02184

Reicher, S. (2020, September 9). Scapegoating young people for Britain's rising coronavirus rates is a poor strategy. The Guardian.

Rickwood, D. J., Deane, F. P., Wilson, C. J., \& Ciarrochi, J. (2005). Young people's help-seeking for mental health problems. Australian E-Journal for the Advancement of Mental Health, 4, 218-251. https://doi.org/10.5172/jamh.4.3.218

Rotter, J. B. (1966). Generalized expectancies for internal versus external control of reinforcement. Psychological Monographs: General and Applied, 80, 1-28. https://doi.org/10.1037/h0092976

Save the Children. (2020). "Children at risk of lasting psychological distress from coronavirus lockdown": Save the children. https://www.savethechildren.net/news/'children-risk-lasting-psychological-distress-coronavirus-lockdown'-save-children

Scott, S. R., Rivera, K. M., Rushing, E., Manczak, E. M., Rozek, C. S., \& Doom, J. R. (2021). “I hate this”: A qualitative analysis of adolescents' self-reported challenges during the COVID-19 pandemic. Journal of Adolescent Health, 68(2), 262-269.

Page $13 / 15$ 
Sell, T. K., Boddie, C., McGinty, E. E., Pollack, K., Smith, K. C., Burke, T. A., \& Rutkow, L. (2017). Media messages and perception of risk for Ebola virus infection, United States. Emerging Infectious Diseases, 23(1), 108-111. https://doi.org/10.3201/eid2301.160589

Siddaway, A. P. (2020). Multidisciplinary research priorities for the COVID-19 pandemic. The Lancet Psychiatry, 7(7), e43. https://doi.org/10.1016/S22150366(20)30220-0

Stapley, E., Demkowicz, O., Eisenstadt, M., Wolpert, M., \& Deighton, J. (2020). Coping with the stresses of daily life in England: a qualitative study of self-care strategies and social and professional support in early adolescence. Journal of Early Adolescence, 4O(5). https://doi.org/10.1177/0272431619858420

Sumter, S. R., Bokhorst, C. L., Steinberg, L., \& Westenberg, P. M. (2009). The developmental pattern of resistance to peer influence in adolescence: will the teenager ever be able to resist? Journal of Adolescence, 32, 1009-1021.

The British Psychological Society. (2014). Code of Human Research Ethics. In The British Psychological Society.

http://www.bps.org.uk/sites/default/files/documents/code_of_human_research_ethics.pdf

The Lancet Child \& Adolescent Health. (2020). Pandemic school closures: risks and opportunities. The Lancet Child and Adolescent Health, 4(5), 341. https://doi.org/10.1016/S2352-4642(20)30105-X

The Prince's Trust, \& YouGov. (2020). Young people in lockdown: A report by The Prince's Trust and YouGov. https://www.princestrust.org.uk/Document_News_YPIL.pdf

Umberson, D., Crosnoe, R., \& Reczek, C. (2010). Social relationships and health behavior across life course. Annual Review of Sociology, 36, $139-157$. https://doi.org/10.1146/annurev-soc-070308-120011.Social

Xiong, J., Lipsitz, O., Nasri, F., Lui, L. M. W., Gill, H., Phan, L., Chen-Li, D., lacobucci, M., Ho, R., Majeed, A., \& McIntyre, R. S. (2020). Impact of COVID-19 pandemic on mental health in the general population: A systematic review. Journal of Affective Disorders, 277(July), 55-64. https://doi.org/10.1016/j.jad.2020.08.001

Yardley, L. (2000). Dilemmas in qualitative health research. Psychology and Health, 15, 215-228. https://doi.org/10.1080/08870440008400302

Yardley, L. (2015). Demonstrating validity in qualitative psychology. In J. A. Smith (Ed.), Qualitative psychology: A practical guide to research methods (3rd ed., pp. 257-272). SAGE Publications Ltd.

Zarrett, N., \& Eccles, J. S. (2006). The passage to adulthood: challenges of late adolescence. New Directions for Youth Development, $2006,13-28$. https://doi.org/10.1002/yd.179

\section{Box 1}

Due to technical limitations, Box 1 can be found in the Supplemental Files.

\section{Figures}




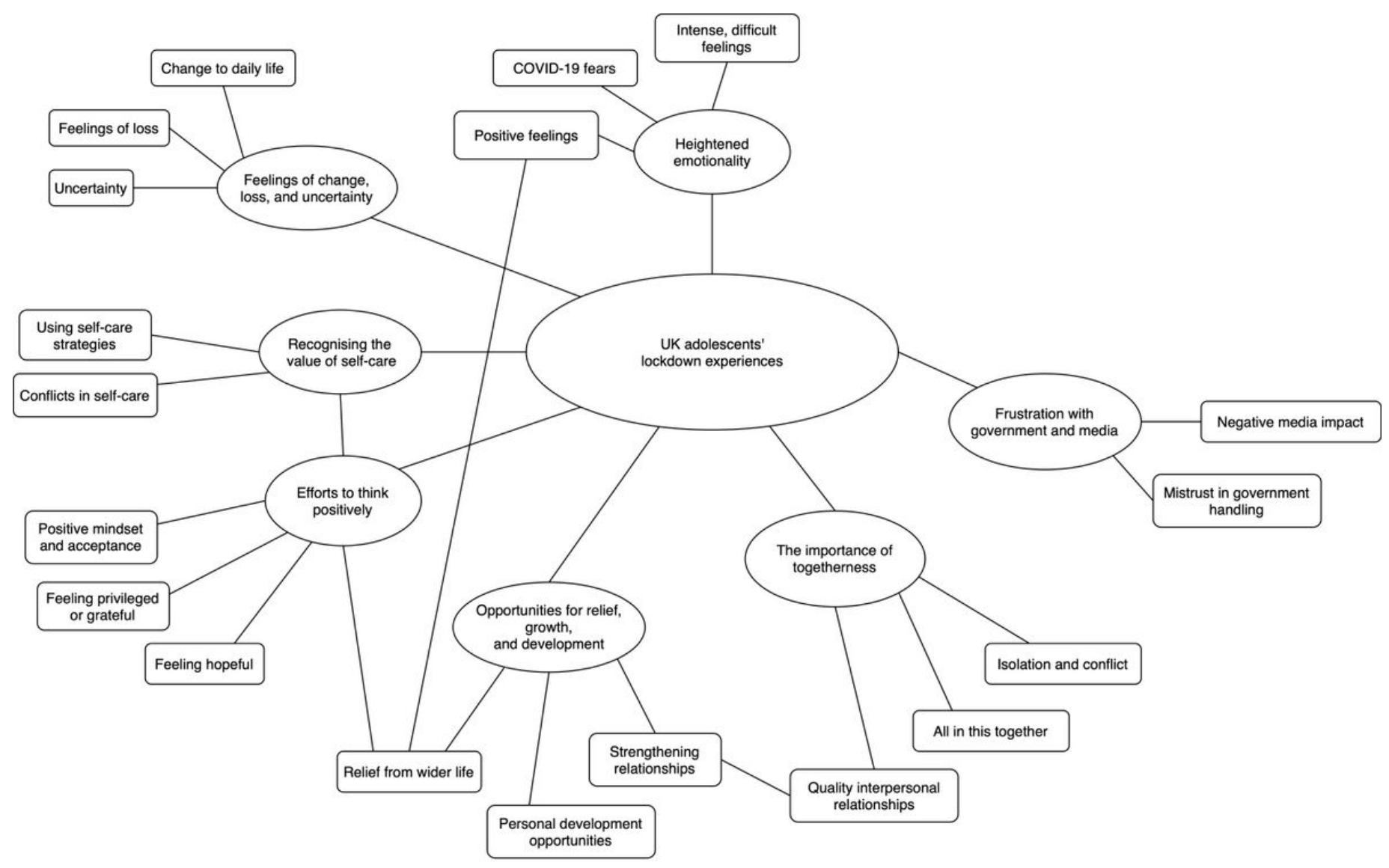

Figure 1. Thematic map of main themes and associated subthemes.

\section{Figure 1}

Thematic map of main themes and associated subthemes.

\section{Supplementary Files}

This is a list of supplementary files associated with this preprint. Click to download.

- Box1.pdf 